\title{
A new route to exposed thermal mass: Sound absorbing poured concrete
}

\author{
S. Lombardo, MEng (hons) \\ Researcher, University of Bath, BA2 7AY \\ J J Orr, MEng (hons) PhD
}

Lecturer in Civil Engineering, Department of Architecture and Civil Engineering, University of Bath, BA2

$$
\text { 7AY }
$$

\section{Corresponding Author}

+44 (0)7980 $434294 \quad$ j.j.orr@bath.ac.uk

D A Coley, BSc, PhD

Professor of Low Carbon Design, Department of Architecture and Civil Engineering, University of Bath,

BA2 7AY

M J Wood, MEng (Hons) PhD

Researcher, College of Engineering, Mathematics and Physical Sciences, University of Exeter, EX4 4SB 


\begin{abstract}
This paper investigates the novel possibility of utilising the structural concrete floor slab as a means of providing additional mid to low frequency sound absorption through the addition of cavities on the ceiling side, formed using flexible formwork, acting as Helmholtz resonators. Mid to low frequency sound absorption in rooms is typically achieved through the use of perforated plasterboard or a suspended tile-in-grid system. Such an approach can separate the room from the thermal mass of the ceiling above, leading to higher peak temperatures or increased cooling load. Suspended ceilings can also increase the embodied energy of the building and limit the potential for stack effect ventilation by reducing room height. In this work, frequency dependent absorption coefficients of perforated concrete samples were measured using an impedance tube test. The results were found to agree with a theoretical analysis, suggesting that it would be relatively easy to predict the performance of perforations of other depths and diameters including those targeted at absorbing higher frequencies.
\end{abstract}




\section{Practical application}

The measurements indicate that such a slab could be used as a practical replacement for perforated plasterboard or a tile-in-grid system. This would allow the slab to be tuned to the building's acoustic performance and structural requirements. The approach has the potential to: 1) reduce the embodied and operational energy of buildings; 2) improve thermal comfort; and 3) create a better acoustic environment in situations where surface robustness or longevity is important, for example, public stairwells, pathways under roads and metro stations. 


\section{Introduction}

The fraction of sound that is absorbed by any material is characterised by its absorption coefficient $(\alpha)$ which varies with the frequency of the sound and takes a value of between 0 (perfect reflection) and 1 (perfect absorption). Most building elements that provide acoustic absorption are better at absorbing high frequency sound than low, making the principal challenge of building acoustics one of absorbing low frequency sound. Smooth poured concrete for example has $\alpha \leq 0.05$ over the frequency range 125 to $1000 \mathrm{~Hz}^{1}$, a level of sound absorption that provides very little acoustic control of a space.

Many spaces use a secondary suspended ceiling made of perforated plasterboard or a tile-in-grid system to provide mid to low frequency absorption ${ }^{2}$ (Figure $1(a)$ ). Such systems help to cover up services but 1) can be aesthetically unpleasing and 2) prevent air from fully interacting thermally with the structural concrete. This loss of access to the thermal mass can increase peak room temperatures ${ }^{3}$, with a subsequent need to increase the size of cooling systems that negatively impacts on energy use. Suspended ceilings additionally reduce room heights, potentially hindering the effectiveness of natural ventilation strategies.

If the underside of poured concrete slabs were made to absorb lower frequency sound, the secondary ceiling could be dispensed with, although high frequency wall absorption or carpets would still be required. This would save on construction costs while also reducing the embodied energy of the building, the cooling energy consumption and the 
cooling plant size. It is proposed to achieve this by casting Helmholtz resonators into the slab soffit (Figure 1(b) and Figure 2). If realised, such acoustic concrete surfaces have other potential benefits. Aggressive environments such as subways, metros, stairwells and car parks would benefit through a reduction in background noise, making these spaces potentially less threatening.

\section{Aims}

This paper shows how a new concrete casting technique might be used to produce sound absorbing concrete structures by forming voids in the surface zone. A simple model of Helmholtz resonators is proposed and verified against test data, thereby providing a way to tune concrete surfaces to the acoustic requirements of a space. Consideration is also given to possible construction techniques for creating the required cavities and whether such acoustically optimised concrete structures could plausibly be used in practice to provide enough absorption to improve the acoustic performance of a space.

\section{Background}

\subsection{Flexible formwork}

Concrete structures are often prismatic, with constant steel reinforcement ratios, having constant moment and shear capacity along their length. Such an approach, constructed using rigid steel or timber formwork, means much of the structure is underutilised. Optimisation of the structural design can result in non-prismatic 
elements, whose form reflects the requirements of the loading envelope, although such an approach is expensive to undertake with conventional formwork.

Flexible formwork replaces rigid systems with lightweight, high strength sheets of fabric and allows a vast range of new geometries to be produced (Figure 3). Work by Orr, Darby ${ }^{4}$ has shown that following simple optimisation processes to design variable cross section elements that are cast in flexible formwork, material savings of up to $40 \%$ can be achieved. Combining structural optimisation with acoustic performance would provide significant additional benefits for concrete structures, if the flexible mould can be used to create a perforated surface zone.

Using sheets of fabric or paper draped between timber floorboards as formwork for a reinforced concrete floor slab, Gustav Lilienthal ${ }^{5}$ effectively initiated the use of fabric formwork in concrete construction. Following closely from the work of Lilienthal, but having the distinction of being rather more prolific, James Waller used hessian fabrics in a patented method for the construction of structural elements. Similar patents used fabric as formwork in hydraulic structures including canals ${ }^{6}$ and he later used sheets of hessian draped between temporary arched formwork to create thin, efficient corrugated shells.

Flexible formwork is also used in both offshore and geotechnical engineering ${ }^{7}$. The development of low cost, high strength, durable, synthetic fabrics in the 1960s allowed more complex shapes to be produced, catalysing a revolution in the architectural use of flexible formwork ${ }^{8}$. 
Architectural developments ${ }^{9-11}$ as well as structural engineering and optimisation advances $^{4,12,13}$ have demonstrated the large material savings that flexible formwork facilitates, making this an increasingly interesting topic for sustainable construction ${ }^{14}$.

In addition, flexible formwork can provide significant durability benefits to the concrete structure. By using a permeable mould (such as a woven fabric) water and air are allowed to escape from the concrete mould during curing. It has been shown that permeable fabric moulds can provide a $50 \%$ reduction in both the chloride diffusion coefficient and the coefficient of carbonation ${ }^{15}$. These combined results demonstrate that fabric formwork may be used to create optimised structures where strength and durability are provided only where they are needed.

Woven synthetic fabrics provide an excellent formwork material. They are inexpensive, strong, do not adhere to concrete, can be cleaned and reused multiple times, and allow air and water to escape the mould during curing. Finally, flexible formwork techniques are globally accessible due to their low technological requirements, making lowercarbon construction something that is easily achieved.

\subsection{Helmholtz resonators}

The operating principles behind Helmholtz resonators have been known for more than 160 years ${ }^{16}$ but have been used to modify space acoustics for many centuries. The basic principle uses an enclosed volume with a narrow neck to absorb sound through 
resonance, the air in the neck acting like a mass and the air in the volume like a spring
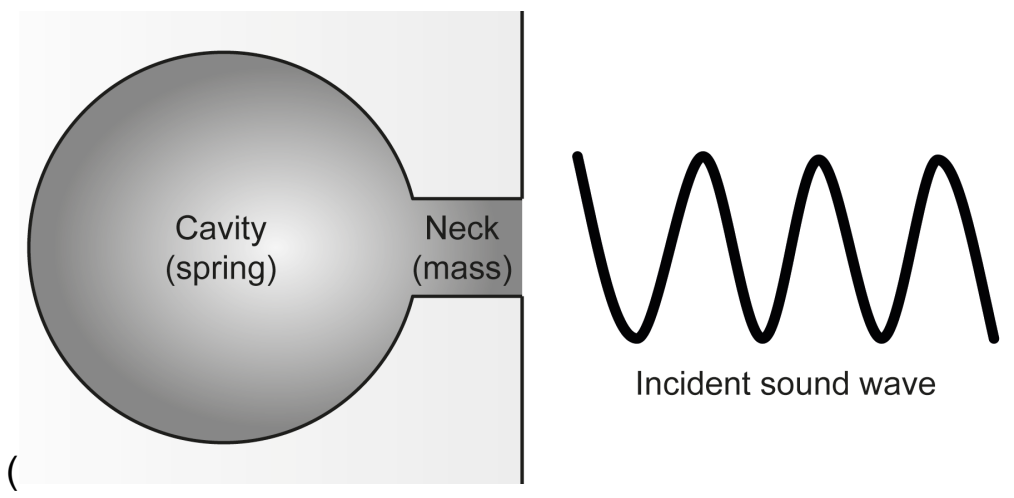

Incident sound wave

Figure 2). The addition of absorbing material, such as compressed mineral wool, into the cavity further improves absorption at frequencies either side of the resonant frequency. This approach has been utilised to create sound absorbing blockwork for walls $^{17}$ and slot resonators ${ }^{18}$. Here, we extend the idea to poured concrete slabs for the first time, in a way that has the potential to be highly cost effective. This new approach could be compared to the slot resonator approach used with poured concrete walls ${ }^{18}$ or the embedding of sintered foam glass granules into prefabricated sections laid into a floor ${ }^{19}$.

Rayleigh ${ }^{20}$ developed the classical mathematical approach to Helmhotz resonators, although his method used many assumptions and neglected variables such as cavity shape. Ingard ${ }^{21}$ aimed to reduce the discrepancies between theoretical and experimental results and developed an end correction method to account for multidimensional wave propagation. However this method was still somewhat inaccurate, with experimental results deviating by as much as $14 \%$ from theory due to 
additional motion of air mass on both sides of the neck ${ }^{22}$. Alster ${ }^{22}$ addressed this by a mass spring analogy, significantly improving the accuracy of the theory.

More recent developments ${ }^{23,24}$ have continued to show that the key parameters that account for the amount and frequency of absorption depends on the size of the aperture, the percentage of the surface which is the aperture, the depth of the neck, the size of the cavity and the flow resistivity of any materials in the cavity or neck.

\section{Theoretical Model}

The following theoretical model was used to predict absorption coefficients over the frequency range $250-1000 \mathrm{~Hz}$, which were then compared with the experimental results.

The absorption coefficient of a Helmholtz resonator depends on the impedance value of the cavity, Eq. $(1)^{25}$, which in turn depends on geometric variables such as cavity shape, cavity depth and neck diameter (
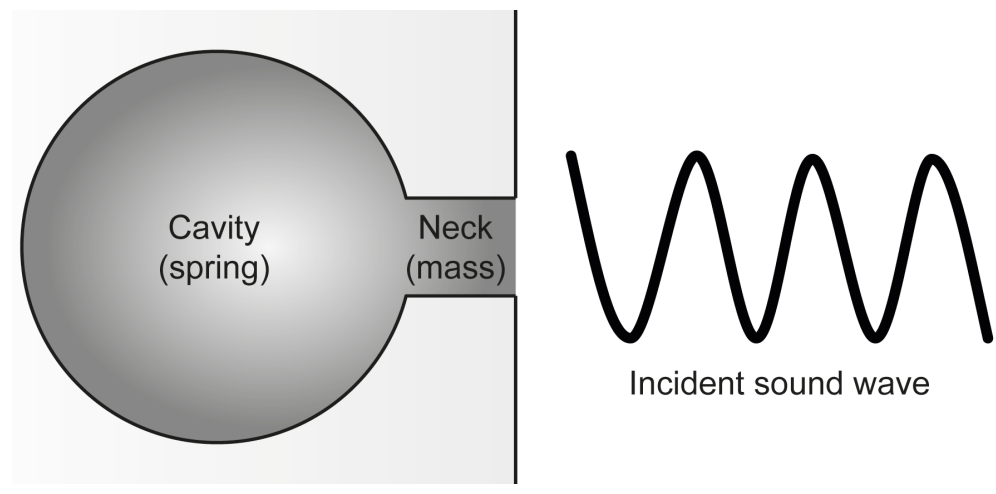

Incident sound wave 
Figure 2).

$$
\alpha=1-\frac{\left(z_{3}-c \rho\right)^{2}}{\left(z_{3}+c \rho\right)^{2}},
$$

where $\alpha$ is the absorption coefficient; $z_{3}$ is the total impedance of the Helmholtz resonator; $c=$ speed of sound; $\rho=$ density.

The transfer matrix method, discussed below, is a powerful technique for modelling sound propagation using a wave approach and obtaining $Z_{3}$. Assuming there are only plane-waves between layers, the surface pressure of one layer can be related to the next (Figure 4).

Applying Snell's law to Figure 4 allows Eq.(2) to be derived to calculate the $x$ component of the wave number $(k)$ :

$$
k_{x i}=k_{i} \sqrt{1-\sin \phi}=\sqrt{k_{i}^{2}-k_{i+1}^{2} \sin \psi} .
$$

The speed of sound in many porous absorbers is small in comparison to air, and so $\phi$ can be assumed to be zero, and hence $k_{x i}=k_{i}$. Surface impedance values at each layer are then given by Eq.(3). The relationship that enables this, relates the surface impedance at $\left(x=x_{i+1}\right)$ to impedance at $\left(x=x_{i}\right)$. 


$$
z_{s i+1}=\frac{-j z_{s i} z_{i} \frac{k_{i}}{k_{x i}} \cot \left(k_{x i} d_{i}\right)+z_{i}\left(\frac{k_{i}}{k_{x i}}\right)^{2}}{z_{s i}-z_{i} \frac{k_{i}}{k_{x i}} \cot \left(k_{x i} d_{i}\right)},
$$

where $z s i$ is the surface impedance at $x=x_{i}, z_{s i+1}$ is the surface impedance at $x=x_{i+1}, d_{i}$ is the cavity depth $k_{i}$ is the wave number in the $\mathrm{i}^{\text {th }}$ layer and $x_{i}$ and $x_{i+1}$ are defined in Figure 4.

Where no porous absorption is used there is only one layer of surface absorption to be considered and Eq.(3) simplifies to:

$$
z_{1}=-j z_{i} \cot \left(k_{i} d_{1}\right)
$$

where $k_{i}$ is the wavenumber of the porous absorbent and $z_{i}$ the characteristic impedance.

When absorption is used it is assumed to fill the entire cavity. Surface impedance of the absorber is then simplified to:

$$
z_{2}=\frac{1}{\varepsilon}(2 \delta a+t) j \omega \rho+z_{1}
$$

where $\varepsilon=$ fraction open area; $\delta=$ end correction factor, assumed to be $0.85^{25} ; a$ is the cavity radius; $t=$ neck depth (sheet thickness); $\omega=$ angular frequency; $\rho=$ density of air; and $Z_{1}=$ impedance at the top of the air layer. 
Methods to account for the mass of the vibrating 'spring' (neck volume) have developed over time, the formulae varying depending on the application. Guess ${ }^{26}$ investigated the effect of radiation impedance and mutual perforation interaction on the spring mass, concluding with Eq.(6):

$$
m=\frac{\rho}{\varepsilon}\left[t+2 \delta a+\sqrt{\frac{8 v}{\omega}}\left(1+\frac{t}{2 a}\right)\right]
$$

where $m=$ spring mass and $v=$ air viscosity.

Guess ${ }^{26}$ accounted for losses in the Helmholtz resonator using Eq.(7). This allowed the absorption coefficient and the surface impedance to be determined for varying frequencies. Perforations that are sub-millimetre are not considered and the acoustic resistance, $r_{m}$ is given by:

$$
r_{m}=\frac{\rho}{\varepsilon} \sqrt{8 v \omega}\left(1+\frac{t}{2 a}\right)
$$

From Eq.(6) and Eq.(7), Allard ${ }^{27}$ developed an equation for calculating the impedance of the Helmholtz resonator, Eq.(8).

$$
z_{3}=\frac{\rho}{\varepsilon}\left(\frac{t}{2 a}+1\right) \sqrt{8 v w}+(2 \delta a+t) \frac{j \omega p}{\varepsilon}+z_{2}
$$




\section{Application}

The practicality of casting a useful Helmholtz resonator into a concrete surface to provide acoustic benefits were initially explored using the above theoretical model. This gave estimates of the absorption that might be achieved with various cavity sizes and neck lengths, and suggested that casting was both possible and practicable with cavities whose dimensions would not compromise the structural performance of a floor.

In the theoretical model, neck depth was found to have little effect on maximum absorption and resonance frequency and therefore neck thickness was designed with the sole purpose of accommodating an absorbent layer of approximately $20 \mathrm{~mm}$ in depth. Two cavity diameters, of $35 \mathrm{~mm}$ and $50 \mathrm{~mm}$, were selected for experimental testing based on predictions of the theoretical model. The modelled distance between cavities cast into the concrete was chosen as $60 \mathrm{~mm}$.

\subsection{With no absorptive material}

The theoretical model confirmed that average absorption with no absorptive material in the neck depends little on cavity depth but is sensitive to neck radius. Figure 5 shows the optimum neck radius between $125 \mathrm{~Hz}$ and $1000 \mathrm{~Hz}$ to be $9 \mathrm{~mm}$, with a calculated resonance frequency of $511 \mathrm{~Hz}$. As expected, the model shows a characteristic Helmholtz resonator behaviour, with a sharp peak near the resonance frequency (a smaller neck radius would be beneficial for better low-frequency absorption performance). 


\subsection{With absorbent material in the neck cavity}

With the addition of absorptive material of resistivity $=20000$ rayls $/ \mathrm{m}$ a neck radius of $15 \mathrm{~mm}$ achieved the highest average absorption coefficient $(0.610)$, although this was at the cost of reduced low frequency absorption, Figure 6.

As expected, the results show a broader bandwidth to the absorption coefficient and no true resonant peak, with much greater high frequency $(1000-2000 \mathrm{~Hz})$ absorption when compared to the results with no absorbent material. Significantly lower absorption was observed at frequencies below $400 \mathrm{~Hz}$ and average absorption was dramatically reduced. This effect occurs as the 'mass' in the neck of the resonator is prevented from moving and contributing to the absorption mechanism, as described in §3.2.

\section{Acoustic Testing}

\subsection{Construction}

Three cylindrical samples were constructed in a $\varnothing 100 \mathrm{~mm} \times 200 \mathrm{~mm}$ impermeable plastic mould, as described by Table 1. A flexible balloon membrane was used to form the spherical void by partially inflating the balloons and filling them with sand until the desired sphere dimensions were obtained. Plastic tubing was used to create the required neck diameter. Samples 2 and 3 were tested with and without absorbent material placed in the neck (denoted by A and B). Sample 1 contained no void. 
A concrete mix prepared in accordance with BRE guidance ${ }^{28}$ was used with a compressive strength at 28 days of $30 \mathrm{MPa}$. The construction process for each sample is illustrated in Figure 7.

For real applications it is envisioned that the fabric formwork would be in the form of a very flexible sheet shaping the width of the slab and be used to form both the voids and the surface of the panel (Figure 8).

An alternative would be to combine the approach with that used in Spherical Void Formations (SVFs). This approach has been in used in Europe to produce lightweight floors for over a decade and has been increasingly incorporated within biaxially reinforced concrete flat-slab systems (Figure 9) to give floors with increased stiffness as well as savings in energy, carbon and materials. Only a small additional tube connecting the permanent plastic spheres to the lower surface would be required to create a Helmholtz resonator device in a highly cost-effective manner.

\subsection{Results}

Impedance tube tests ${ }^{29}$ were performed to determine the normal incidence absorption coefficient for each of the test samples and compared to the performance of a commercial plasterboard suspended ceiling . Samples 2 and 3 were tested at 250, 500 and $1000 \mathrm{~Hz}$. Sample 1 was tested at $250 \mathrm{~Hz}$ to provide a datum value. A summary of the results is provided in Table 2. 


\subsubsection{Sample 1, no cavity}

Results from the plain concrete sample at $250 \mathrm{~Hz}$ were used as a datum point from which to compare the subsequent tests. Other frequencies were not tested but no significant variations with frequency should be expected for hard materials such as plain concrete over this range of frequencies.

\subsubsection{Sample $2,50 \mathrm{~mm}$ cavity}

Fairly typical Helmholtz behaviour was achieved for Sample 2A although a low average absorption coefficient was seen (Figure 10). This is attributable to a substantial decrease in absorption at frequencies above $450 \mathrm{~Hz}$. The resonant response lies in a narrow range of $250-450 \mathrm{~Hz}$, where the average absorption coefficient is greatly increased.

Introducing absorbent material into the neck (Sample 2B) caused a significant change in absorption. Minimum absorption occurs at a value of $450 \mathrm{~Hz}$, with absorption increasing at higher and lower frequencies. This behaviour is likely to be due to the introduction of the absorbent material, although it might also be due in part to an anomaly in the $250 \mathrm{~Hz}$ measurements. Nevertheless, resonant behaviour was not observed and low frequency absorption was limited.

Experimental results for Samples $2 \mathrm{~A}$ and $2 \mathrm{~B}$ are compared to theoretical predictions in Table 2. 


\subsubsection{Sample 3, 35mm cavity}

Typical Helmholtz behaviour was observed for Sample 3A (Figure 11) and higher average absorption being achieved. Lower absorption is found below $400 \mathrm{~Hz}$, although the absorption coefficient is still far more than that achieved using a plain concrete sample. Good absorption is achieved in the range of $400-1000 \mathrm{~Hz}$, and occurs over a much wider bandwidth than with Sample 2A.

When the absorbent neck material (Sample 3B) was introduced, some resonant behaviour remains, although absorption occurs across a wider bandwidth with a lower maximum absorption. Slightly higher average absorption is achieved by incorporating absorbent material into the neck cavity.

Experimental results for Samples $3 \mathrm{~A}$ and $3 \mathrm{~B}$ are compared to theoretical predictions in Table 2.

\section{Discussion}

Sample 1 achieved a low absorption coefficient similar to the 0.1 value accepted in many standard tables of absorption coefficients for rough concrete ${ }^{30}$.

Experimental results for Samples 2 and 3 varied considerably, with Sample 3 showing a more resonant behaviour with and without the incorporation of absorbent material in the neck. Sample 2 showed limited resonance behaviour without absorbent material 
(Sample 2A) and an interesting response when absorbent material was added to the neck (Sample 2B).

It is clear that the absorption coefficients achieved are sufficient for use in practical settings, with results approaching those recorded by British Gypsum for commercial resonant panel systems such as Gyptone (Figure 10 and Figure 11), but for a surface that is far more robust.

The impedance tube results are for a single void, but the method would also apply to a surface containing a regular array of cavities. The experimental samples had a diameter of $100 \mathrm{~mm}$. A surface with a lower cavity spacing would achieve a higher absorption coefficient. It would also be informative to test a wider range of void diameters.

The mathematical model presented above is extended in Cox and D'Antonio ${ }^{25}$ (p348) and predicts that if the open area increased by reducing the centre-centre spacing from $100 \mathrm{~mm}$ to $60 \mathrm{~mm}$ the average absorption coefficient $(250-1000 \mathrm{~Hz})$ and the frequency of the peak absorption would increase by $60 \%$. Applying this uplift to the experimental data gives the results in Table 3 .

Greater absorption was observed with a cavity depth of $35 \mathrm{~mm}$ compared to one of $50 \mathrm{~mm}$, although this may be due to cracking found in the $50 \mathrm{~mm}$ cavity caused by air bubbles collecting at the bottom of the balloon during concrete compaction. 


\section{Example application}

In order to demonstrate the potential of the approach in a practical setting, the reverberation time of an empty room has been calculated for a number of different ceiling materials, the acoustic performance of which are given in Table 4, including the perforated concrete panel described in this paper.

The frequency dependent reverberation time $T_{60, f}$ (i.e. the length of time it takes a pulse of sound to decay by $60 \mathrm{~dB}$ ) of a space is commonly calculated using the Sabine formula:

$$
T_{60, f}=0.16 \frac{V}{\sum \alpha_{i, f} S_{i}}
$$

where $V$ is the volume of the room, $S_{i}$, the area of the $i^{\text {th }}$ major surface and the summation is over all surfaces i. $\alpha_{f}$ in Eq.(9) is the random incidence absorption coefficient at frequency $f$, whereas the measurements above are for sound at a normal to the surface; however in what follows this is unlikely to be pertinent as only an example case is discussed.

Room dimensions of $8 \mathrm{~m} \times 8 \mathrm{~m} \times 4 \mathrm{~m}$ were chosen with the floor and walls assumed to be built of common materials with typical abortion coefficients (Table 4). The coefficients assumed for the perforated concrete ceiling are taken from the experimental data (Samples $3 \mathrm{~A}$ and $3 \mathrm{~B}$ ) 
The results are shown in Figure 12. The reverberation time predicted for the room with a perforated concrete ceiling $(0.91 \mathrm{~s}$ at $1000 \mathrm{~Hz})$ is similar to that predicted for Gyptone panels $(0.75 \mathrm{~s}$ at $1000 \mathrm{~Hz})$ and far less than that with a plasterboard or a plain concrete ceiling $(4.17 \mathrm{~s}$ at $1000 \mathrm{~Hz})$. It is noted that the results shown in Figure 12 are likely to slightly overestimate the absorption in some settings, for example stairwells, as the Sabine method relies on an equally distributed sound absorption.

For frequencies above $1 \mathrm{kHz}$ the cavity system could be used in conjunction with opencell porous absorbers to improve speech intelligibility.

\section{Conclusions}

A novel approach to meeting the requirement of wanting to expose thermal mass and still achieving sound absorption has been explored. In contrast to solutions such as sound absorbing rafts, the approach is far more robust. Impedance tube tests were carried out on concrete samples perforated with flexibly formed cavities that exhibited

Helmholtz resonant behaviour. Test results compared qualitatively with those predicted by the theoretical modelling of a spherical cavity, and clearly show that sufficient absorption for practical uses can be accomplished by the introduction of Helmholtz resonators into a poured concrete structure.

Greater absorption was observed with a cavity depth of $35 \mathrm{~mm}$ compared to one of $50 \mathrm{~mm}$, although this may be due to cracking found in the $50 \mathrm{~mm}$ cavity caused by air bubbles collecting at the bottom of the balloon during concrete compaction. 
The results show that the technique could be used to control the reverberation time of a room. In addition, the increase in room volume and thermal mass achieved by omitting suspended ceilings would bring great benefits. The application of flexible formwork as the construction method for such structures is a further innovation that could provide structurally efficient, aesthetically pleasing, acoustically controlled exposed concrete surfaces for new building structures.

It is therefore suggested that the approach has the potential to: 1) reduce the embodied and operational energy of buildings; 2) improve thermal comfort; 3 ) improve the acoustic environment in situations where surface robustness or longevity is important; and 4) make spaces such as stairwells, which can feel threatening to women and others in part due to their poor acoustics, more pleasant places to be.

\section{References}

1. Tapley BD. Eshbach's handbook of engineering fundamentals. New York: John Wiley and Sons, 1990.

2. Saint-Gobain. Gyptone Products. Kalundborg: Saint-Gobain, 2015.

3. Concrete Centre. Thermal Mass - A Concrete Solution for the Changing Climate. Surrey: The Concrete Centre, 2005.

4. Orr JJ, Darby AP, Ibell TJ, Evernden MC and Otlet M. Concrete structures using fabric formwork. The Structural Engineer. 2011; 89: 20-6.

5. $\quad$ Lilienthal LWG. Fireproof Ceiling. In: Office UP, (ed.). USA1899.

6. Waller JHW. Method of building with cementitious material applied to vegetable fabrics. In: Office UP, (ed.). USA1934.

7. Lamberton BA. Fabric forms for concrete. Concrete international. 1989: 58-67.

8. Veenendaal $D$, West $M$ and Block P. History and overview of fabric formwork: using fabrics for concrete casting. Structural Concrete. 2011; 12: 164-77.

9. Araya R and West M. Flat sheet fabric moulds for double curvature precast concrete elements. In: Orr JJ, Evernden M, Darby AP and Ibell PT, (eds.). Second International Conference on Flexible Formwork University of Bath: Bath, 2012. 
10. West M, Araya, R. Fabric formwork for concrete structures and architecture. In: Kröplin B and Onate E, (eds.). International Conference on Textile Composites and Inflatable Structures. Barcelona, Spain: CIMNE, 2009.

11. West M and Araya R. Recent fabric formwork construction projects. In: Orr JJ, Evernden M, Darby AP and Ibell PT, (eds.). Second International Conference on Flexible Formwork. University of Bath: Bath, 2012.

12. Veenendaal D. Evolutionary optimisation of fabric formed structural elements.

Civil Engineering and Geosciences. Delft: University of Delft, 2008, p. 262.

13. Williams CJKW. Meshfree peridynamic computer modelling of concrete in three dimensions using randomly positioned particles. In: Orr JJ, Darby AP, Evernden M and Ibell T, (eds.). Second International Conference on flexible Formwork. University of Bath: University of Bath Press, 2012.

14. Orr JJ, Evernden M, Darby AP and Ibell TJ. Proceedings of the Second International Conference on Flexible Formwork. The Second International Conference on Flexible Formwork. Bath, UK: University of Bath, 2012.

15. Orr JJ, Darby AP, Ibell TJ and Evernden M. Durability enhancements using fabric formwork. fib symposium: Concrete structures for Sustainable Community. Stockholm2012.

16. Helmholtz Hv. On the sensations of tone as a physiological basis for the theory of music (2nd Edition). London: Longmans, Green and Co, 1895.

17. Proudfoot Company Inc. Noise Control and Sound Level Reduction. Monroe, CT: Proudfoot Company Inc, 2013.

18. Arup. Acoustic concrete. Arup, 2015.

19. Pyrotek. REAPOR® sound absorber. 2017.

20. Rayleigh JWS. Theory of Sound. London: Macmillan and Company, 1894.

21. Ingard U. On the theory and design of acoustic resonators. J Acoust Soc Am. 1953; 25: 1037-61.

22. Alster M. Improved calculation of resonant frequencies of Helmholtz resonators. Journal of Sound and Vibration. 1972; 24: 63-85.

23. Glass GK and Buenfeld NR. The influence of chloride binding on the chloride induced corrosion risk in reinforced concrete. Corrosion Science. 2000; 42: 329-44.

24. Sebaa N, Fellah ZEA, Fellah M, Lauriks W and Depollier C. Measuring flow resistivity of porous material via acoustic reflected waves. Journal of Applied Physics. 2005; 98: 10.

25. Cox TJ and D'Antonio P. Acoustic Absorbers and Diffusers. Theory, Design \& Application. London: CRC Press, 2004.

26. Guess AW. Calculation of perforated plate liner parameters from specified acoustic resistance and reactance. J Sound Vib. 1975; 40: 119-37.

27. Allard JF. Propagation of sound in porous media: Modelling Sound Absorbing Materials. London: Elsevier Applied science, 1993.

28. Teychenne DC, Franklin RE and Erntroy HC. Design of normal concrete mixes second edition. In: Establishment BR, (ed.). Watford: Building Research Establishment, 1997. 
29. BSI. BS EN ISO 10534-1. Acoustics Determination of sound absorption coefficient and impedance in impedances tubes Method using standing wave ratio. London: BSI, 2001.

30. Egan MD. Architectural Acoustics. Florida: J Ross Publishing, 2007. 


\section{Figure Captions}

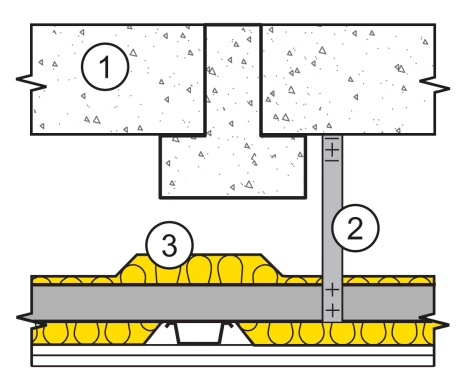

(a) Suspended ceiling. 1: Structural floor; 2: Hanging system and tiles; 3 : Sound absorbing material

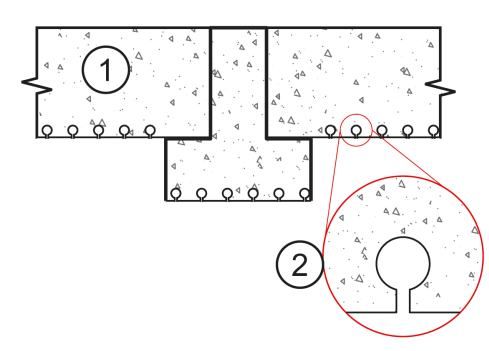

(b) Proposed ceiling.

1: Structural floor; 2: Helmholtz resonators cast into the soffit

Figure 1: Conventional suspended ceiling (left); proposed alternative (right)
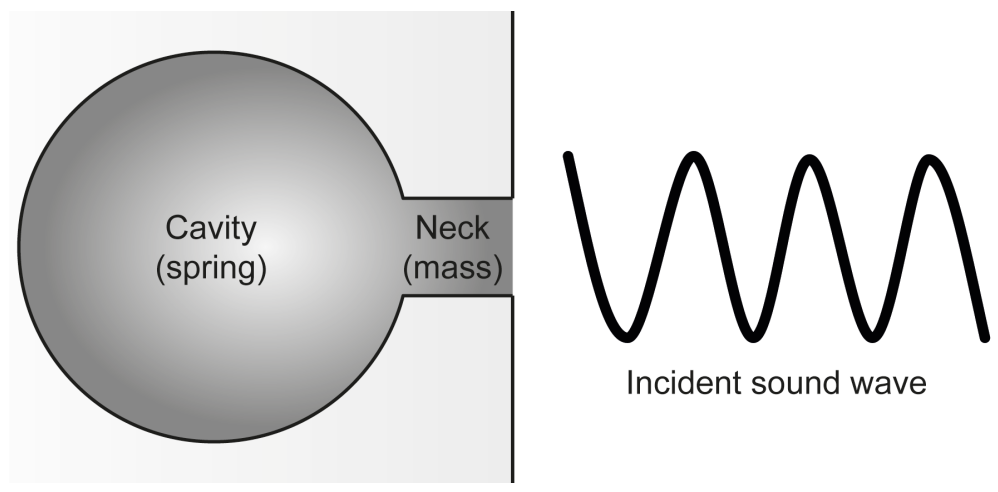

Figure 2: Helmholtz Resonator 

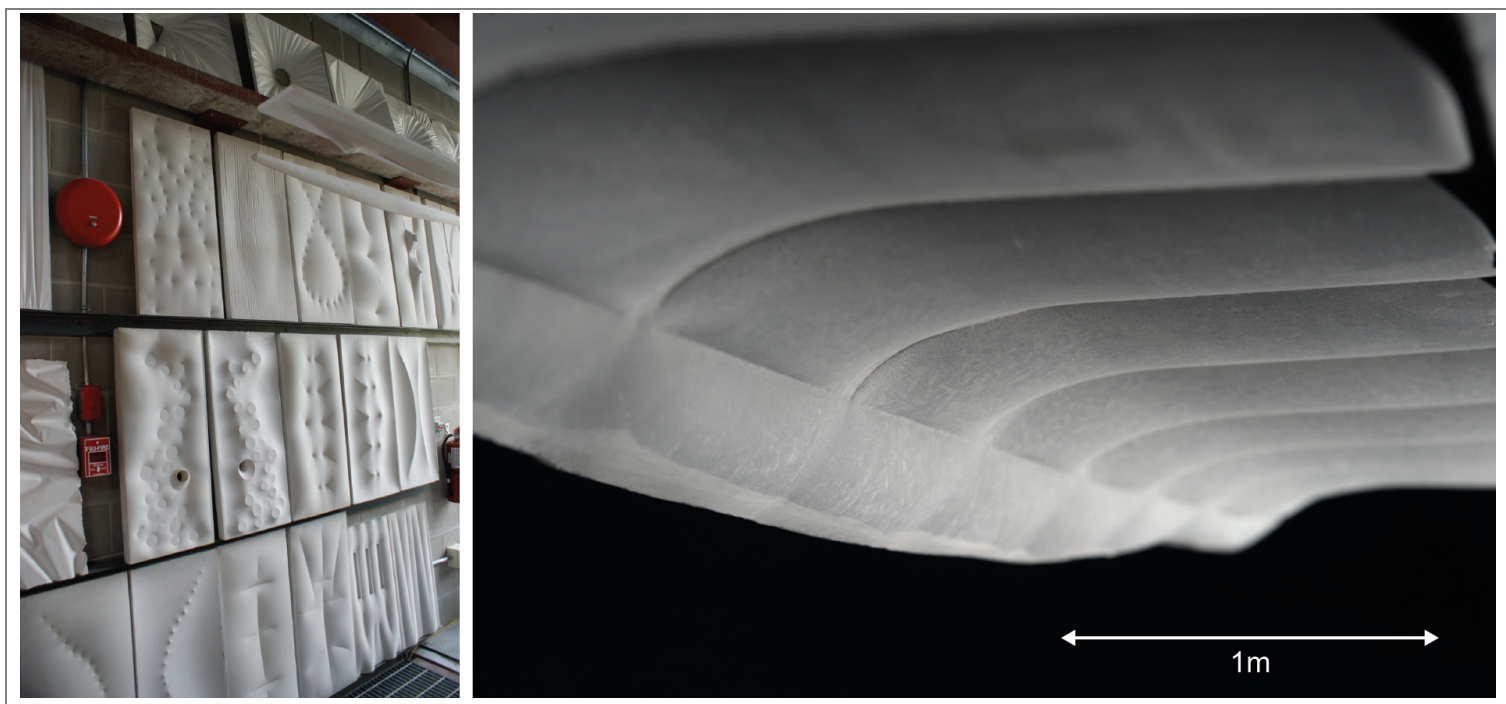

Figure 3: Fabric formed surfaces (left); fabric formed beam (right)

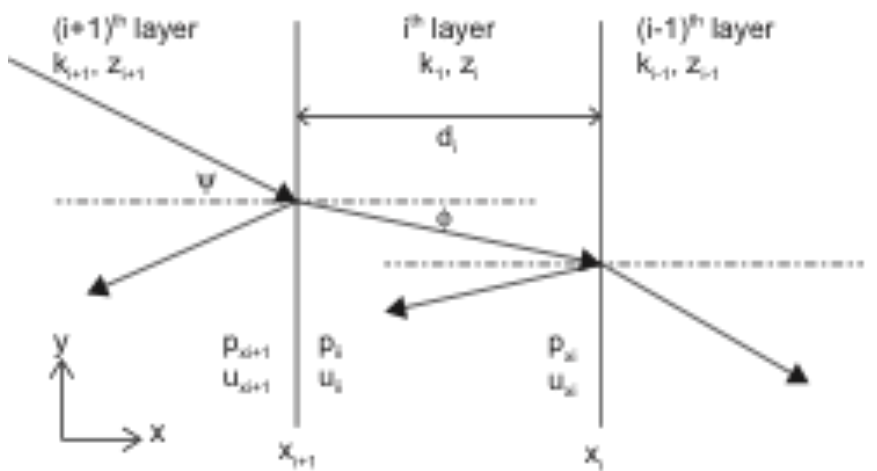

Figure 4: Transfer Matrix Method (after Cox and D'Antonio ${ }^{25}$ ) 


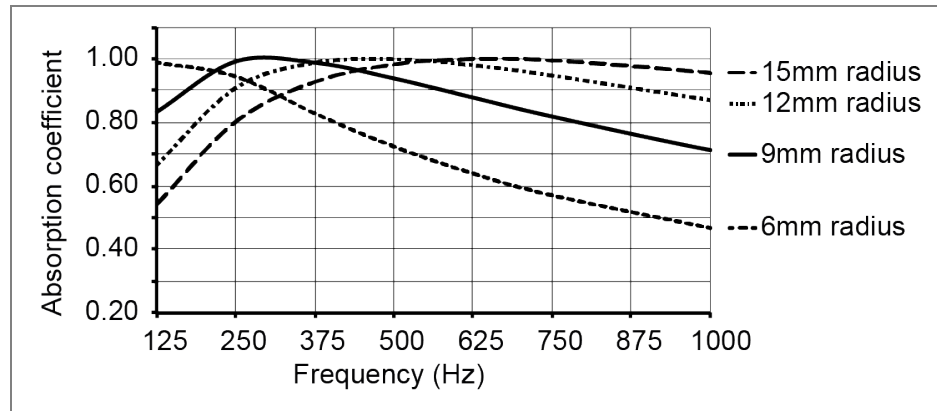

Figure 5: Modelled Absorption coefficient for varying neck radius (no absorptive material in neck)

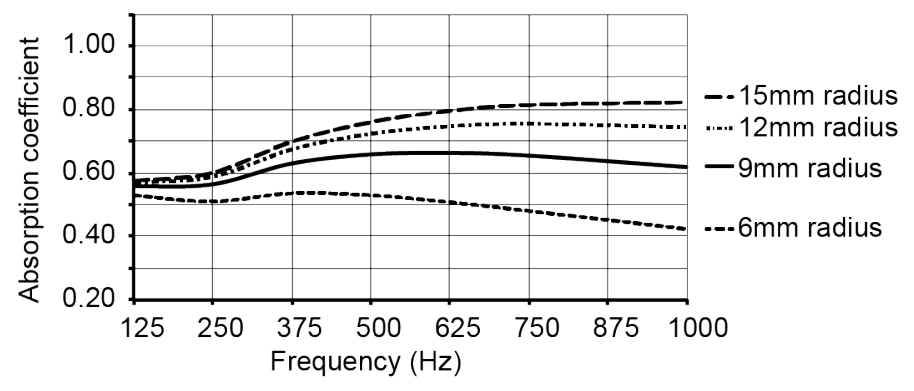

Figure 6: Modelled Absorption coefficient for varying neck radius - with absorptive material in neck
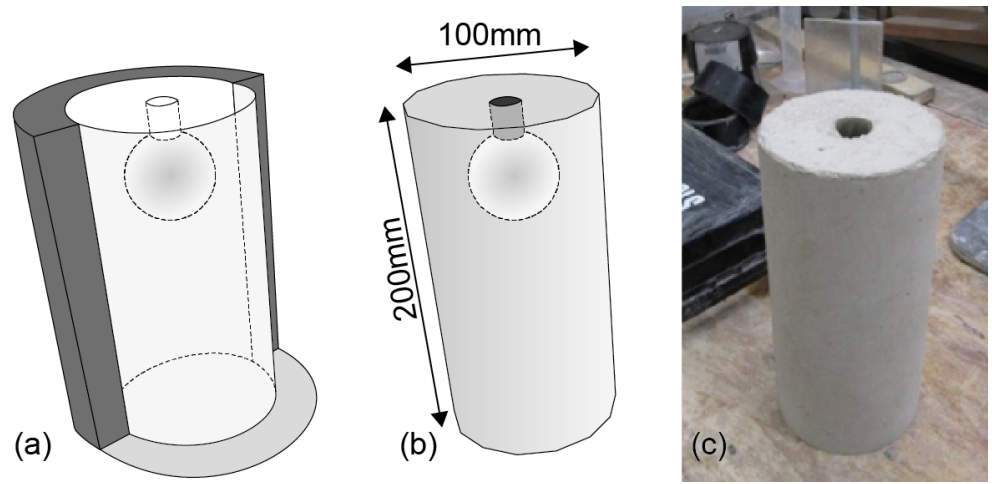

Figure 7: (a) concrete cylinder mould and cavity formwork; (b) absorbent material added to neck of cast sample; (c) example complete sample used in impedance tube tests 


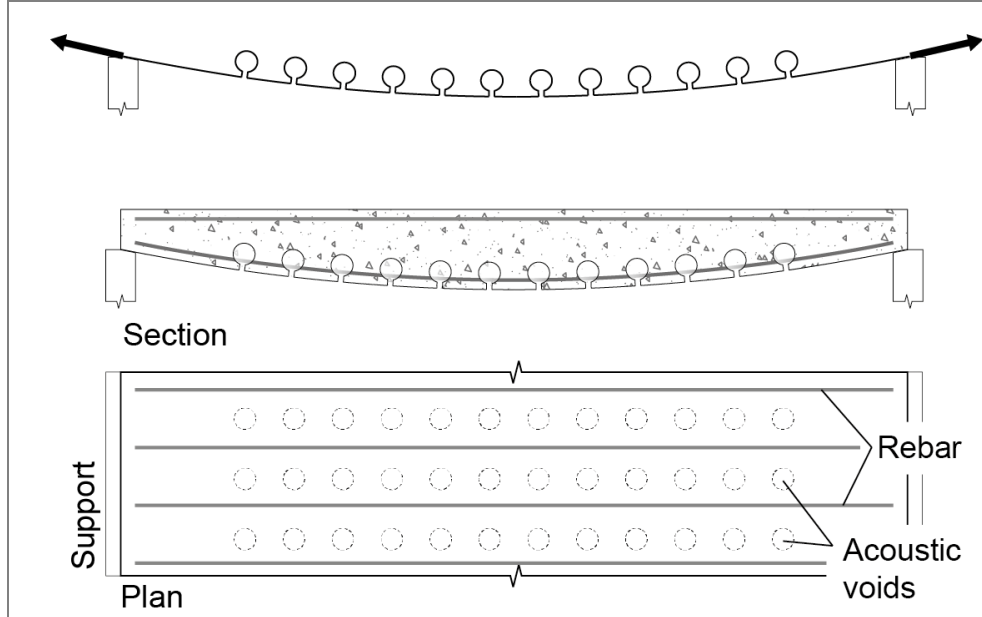

a) Fabric with rigid voids attached hung between supports

b) Rebar and concrete added. Fabric stripped, void formers remain in place.

c) Plan view of slab (one-way spanning)

Figure 8: Application of the method using flexible formwork

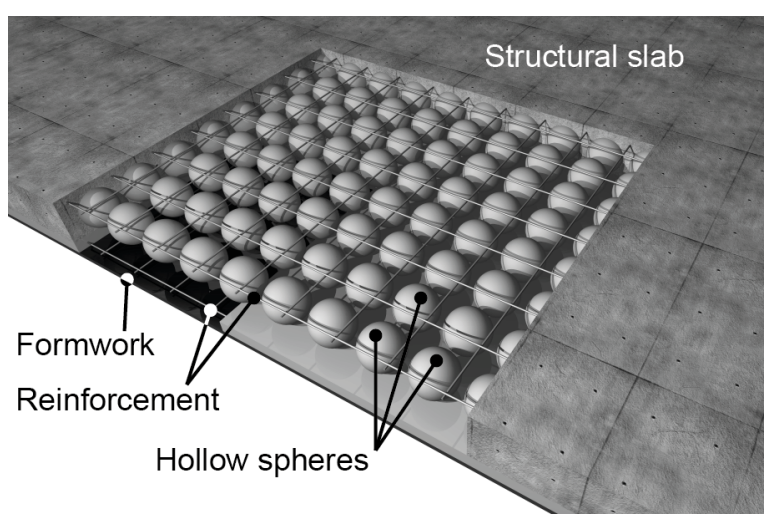

Figure 9: Flat-slab with spherical void formations could be used as a basis for the creation of resonators 


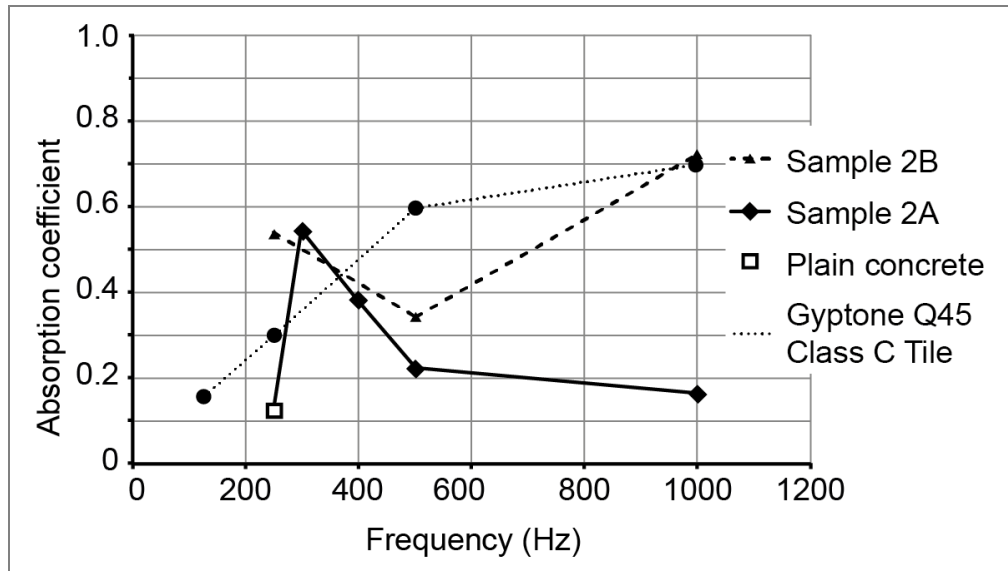

Figure 10: Sample 2A and 2B, absorption coefficient with (2B) and without (2A) absorbent material. The plain concrete data point was found using Sample 1.

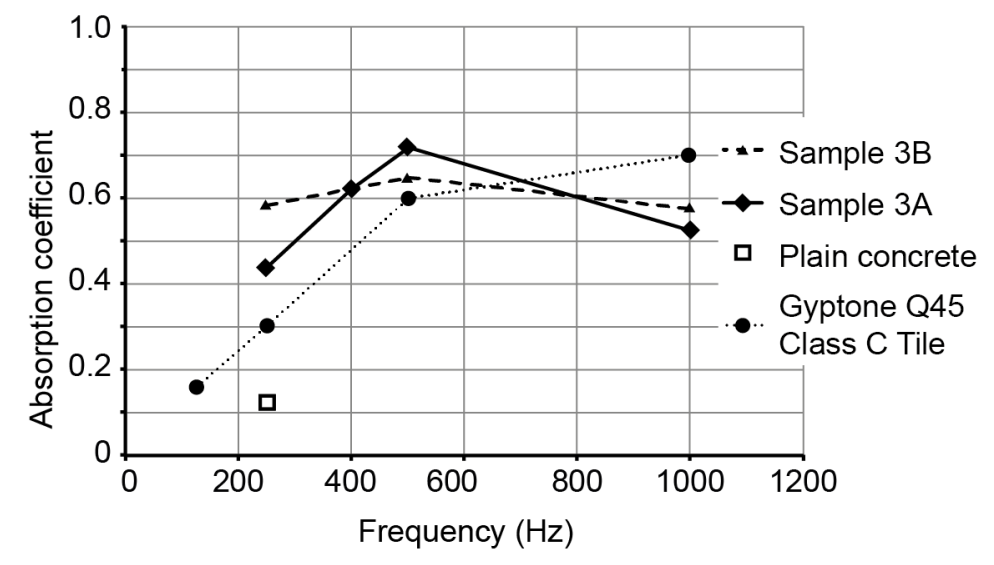

Figure 11: Sample 3A and 3B, theoretical and experimental absorption coefficient results 


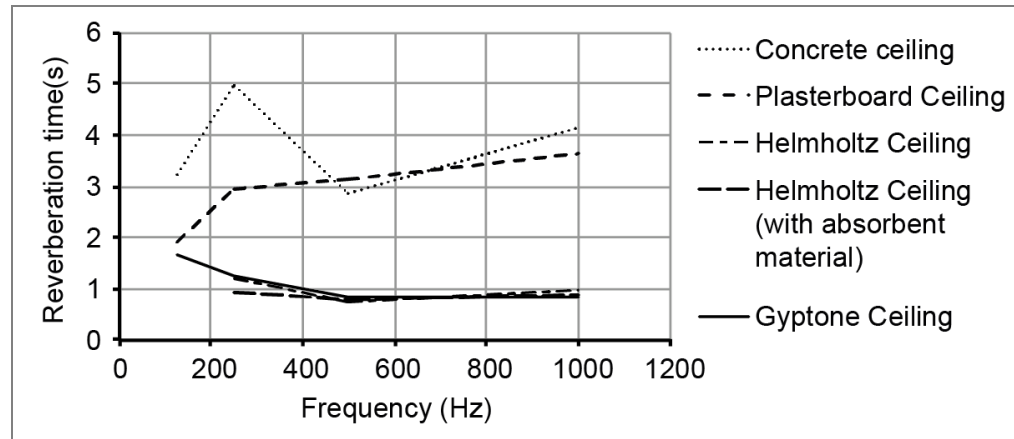

Figure 12: Comparison of reverberation times for a room with different ceiling constructions. 


\section{Tables}

Table 1: Sample dimensions

\begin{tabular}{||l|l|l|l|l|}
\hline Sample & $\begin{array}{l}\text { Neck diameter } \\
(\mathrm{mm})\end{array}$ & $\begin{array}{l}\text { Absorbent } \\
\text { material }\end{array}$ & $\begin{array}{l}\text { Neck depth } \\
(\mathrm{mm})\end{array}$ & $\begin{array}{l}\text { Cavity Diameter } \\
(\mathrm{mm})\end{array}$ \\
\hline 1 & - & - & - & - \\
\hline 2A & 17 & No & 20 & 50 \\
\hline 2B & 17 & Yes & 20 & 50 \\
\hline 3A & 17 & No & 20 & 35 \\
\hline 3B & 17 & Yes & 20 & 35 \\
\hline
\end{tabular}

Table 2: Results summary

\begin{tabular}{|l|l|l|l|l|}
\hline Sample & $\begin{array}{l}\text { Average } \\
\text { experimental } \\
\text { absorption } \\
\text { coefficient }(250- \\
1000 \mathrm{~Hz})(\mathrm{Hz})\end{array}$ & $\begin{array}{l}\text { Experimental } \\
\text { resonance } \\
\text { frequency }(\mathrm{Hz})\end{array}$ & $\begin{array}{l}\text { Theoretical } \\
\text { absorption } \\
\text { coefficient }\end{array}$ & $\begin{array}{l}\text { Theoretical } \\
\text { resonance } \\
\text { frequency }\end{array}$ \\
\hline 1 & $\begin{array}{l}0.125(250 \mathrm{~Hz} \\
\text { only) }\end{array}$ & NA & & \\
\hline $\begin{array}{l}2 \mathrm{~A}(50 \mathrm{~mm} \\
\text { cavity) }\end{array}$ & 0.169 & 315 & 0.695 & 383 \\
\hline $\begin{array}{l}\text { 2B (50mm } \\
\text { cavity with } \\
\text { absorbent } \\
\text { material) }\end{array}$ & 0.533 & NA & 0.473 & NA \\
\hline 3A (35mm) & 0.560 & 505 & 0.880 & 574 \\
\hline $\begin{array}{l}3 \mathrm{~B}(35 \mathrm{~mm} \\
\text { cavity with } \\
\text { absorbent } \\
\text { material) }\end{array}$ & 0.601 & $\mathrm{NA}$ & 0.542 & $\mathrm{NA}$ \\
\hline
\end{tabular}

Table 3: Effect of cavity spacing on absorption coefficient and resonant frequency.

\begin{tabular}{|c|c|c|c|c|c|c|}
\hline \multicolumn{4}{|c|}{ Experimental } & \multicolumn{3}{|c|}{ Factored experimental } \\
\hline Sample & $\begin{array}{l}\text { Cavity } \\
\text { spacing }\end{array}$ & $\begin{array}{l}\text { Experimental } \\
\text { Absorption } \\
\text { Coefficient }\end{array}$ & $\begin{array}{l}\text { Experimental } \\
\text { Resonant } \\
\text { Frequency }\end{array}$ & $\begin{array}{l}\text { Cavity } \\
\text { spacing }\end{array}$ & $\begin{array}{l}\text { Adjusted } \\
\text { Experimen } \\
\text { tal }\end{array}$ & $\begin{array}{l}\text { Adjusted } \\
\text { Experimen } \\
\text { tal }\end{array}$ \\
\hline
\end{tabular}




\begin{tabular}{|c|c|c|c|c|c|c|}
\hline & & & $(\mathrm{Hz})$ & & $\begin{array}{l}\text { Absorption } \\
\text { Coefficient }\end{array}$ & $\begin{array}{l}\text { Resonant } \\
\text { Frequency } \\
(\mathrm{Hz})\end{array}$ \\
\hline $2 \mathrm{~A}$ & $2 d$ & 0.169 & 315 & $1.2 d$ & 0.270 & \begin{tabular}{|l|l}
504 & \\
\end{tabular} \\
\hline $2 \mathrm{~B}$ & $2 d$ & 0.533 & NA & $1.2 d$ & 0.854 & NA \\
\hline $3 \mathrm{~A}$ & $2.86 d$ & 0.560 & 505 & $1.2 d$ & 0.896 & 808 \\
\hline $3 \mathrm{~B}$ & $2.86 d$ & 0.601 & NA & $1.2 d$ & 0.962 & NA \\
\hline
\end{tabular}

Table 4: Material properties assumed for the example room

\begin{tabular}{|c|c|c|c|c|}
\hline Frequency $(\mathrm{Hz}$ & \multirow[t]{2}{*}{125} & \multirow[t]{2}{*}{250} & \multirow[t]{2}{*}{500} & \multirow[t]{2}{*}{1000} \\
\hline Material & & & & \\
\hline Concrete block, painted (wall) & 0.1 & 0.05 & 0.06 & 0.07 \\
\hline Carpet (floor) & 0.01 & 0.02 & 0.06 & 0.015 \\
\hline $\begin{array}{l}35 \mathrm{~mm} \text { perforated concrete ceiling } \\
\text { with absorbent material }\end{array}$ & NA & 0.581 & 0.647 & 0.575 \\
\hline $\begin{array}{l}35 \mathrm{~mm} \text { perforated concrete ceiling } \\
\text { without absorbent material }\end{array}$ & NA & 0.438 & 0.718 & 0.525 \\
\hline Plasterboard ceiling & 0.15 & 0.11 & 0.04 & 0.04 \\
\hline Gyptone ceiling & 0.15 & 0.30 & 0.65 & 0.80 \\
\hline
\end{tabular}

